\title{
BENEFICIAMENTO DE SEMENTES DE NABO FORRAGEIRO ${ }^{1}$
}

\author{
MARCELA CARLOTA NERY², MARIA LAENE MOREIRA DE CARVALHO ${ }^{3}$, \\ JOÃO ALMIR OLIVEIRA ${ }^{3}$, VERÔNICA YUMI KATAOKA ${ }^{4}$
}

\begin{abstract}
RESUMO - O beneficiamento de sementes é uma etapa subsequente à produção que visa aprimorar a qualidade de lotes, tornando-os aptos para a comercialização. Para espécies cujas sementes contêm diferenças na densidade em virtude da desuniformidade de maturação ou muito susceptíveis a danos mecânicos como o nabo forrageiro, é fundamental o conhecimento dos efeitos do beneficiamento no potencial fisiológico dos lotes. Dois lotes da cultivar CATI AL-1000, safra 2006, foram submetidos ao beneficiamento, pela máquina de ar e peneira e mesa de gravidade (descarga superior, intermediária superior, intermediária inferior e inferior) e avaliados em relação a seus aspectos físicos e fisiológicos. Foram determinados o grau de umidade, a pureza, o peso de mil sementes, a germinação, a primeira contagem da germinação, o índice de velocidade de germinação, o estande inicial, a emergência, o índice de velocidade de emergência, a massa seca da parte aérea de plântulas e a sanidade. Concluiuse que, para atender os padrões mínimos de pureza e germinação para comercialização de sementes certificadas de nabo forrageiro, os lotes devem ser beneficiados em máquina de ar e peneiras e mesa de gravidade. $\mathrm{O}$ beneficiamento em máquina de ar, peneiras e mesa gravitacional contribui para o aprimoramento da qualidade fisiológica das sementes de nabo forrageiro. A máquina de ar e peneiras e a mesa gravitacional são equipamentos eficientes para a separação do lote de sementes de nabo forrageiro em frações com qualidade física e fisiológica distintas.
\end{abstract}

Termos para indexação: Raphanus sativus, lotes, qualidade, densidade.

\section{OIL RADISH SEEDS PROCESSING}

\begin{abstract}
Seed Seed processing is a subsequent step for production which aims to improve lot quality, making seeds appropriate for commercialization. For species whose seeds have differences in density due to non-uniform maturation or are very susceptible to mechanical damage, such as the fodder radish, the understanding of the processing effects on the physiological potential of the lots is fundamental. Two lots of the cultivar CATI Al-1000, 2006 harvest, were submitted to processing by air screen separator and gravity table (high, intermediate high, intermediate low and low discharge) and their physiological and physical aspects evaluated. The following were determined: moisture content, purity, weight per thousand seeds, germination, first germination count, germination speed index, initial stand, emergence, emergence speed index, dry matter of seedling aerial part and
\end{abstract}

${ }^{1}$ Submetido em 19/10/2008. Aceito para publicação em 06/06/2009 . Parte da Tese de Doutorado do primeiro autor apresentado a UFLA.

${ }^{2}$ Eng. Agr.; Dr, Departamento de Agronomia, UFVIM, Cep:39100-000, Diamantina-MG - mail: nery.marcela@gmail.com
${ }^{3}$ Eng. Agr.; Dr; Professor Associado, Departamento de Agricultura, UFLA. Caixa Postal 3037, Lavras, MG. CEP: 37200-000.

${ }^{4}$ Eng. Agr.; Dr., Departamento de Ciências Exatas, UFLA. 
health quality. It was concluded that to satisfy the minimum standards of purity and germination for commercialization of certified fodder radish seeds, lots must be processed by air screen separator and gravity table. The air screens machine and air and gravity table are efficient for separating the fodder radish seed lots into fractions with different physical and physiological quality. The lower density fodder radish seeds have lower physiological quality.

Index terms: Raphanus sativus, lots, quality, processing.

\section{INTRODUÇÃO}

O nabo forrageiro, Raphanus sativus L. var. oleiferus Metzg., é uma planta originária da Ásia Oriental e Europa, pertencente à família Brassicaceae, da ordem Caparales, com ciclo anual de inverno (Muzilli, 2002). O fruto é uma síliqua indeiscente, de 3 a $5 \mathrm{~cm}$ de comprimento, contendo de 2 a 10 sementes, com massa de 1000 grãos variando de 6 a 14g, com média de $11 \mathrm{~g}$ (Derpsch e Calegari, 1992).

A utilização de sementes de elevado potencial fisiológico é fundamental, a fim de que sejam evitados problemas como baixo estande, disseminação de doenças e deterioração no armazenamento, entre outros. Um grande desafio para as instituições de pesquisa e empresas produtoras de sementes tem sido a avaliação do potencial fisiológico e a seleção de lotes comerciais. No caso das sementes de nabo forrageiro, as pesquisas ainda são também escassas, o que limita a obtenção e a comercialização de lotes de boa qualidade.

$\mathrm{O}$ beneficiamento de sementes é componente fundamental em qualquer programa organizado de produção de sementes e tem como objetivo beneficiar, favorecer e aprimorar a qualidade das sementes, dando-lhes condições de serem utilizadas pelos produtores (Linares, 1999), e de atenderem os padrões mínimos de comercialização que estão pré-estabelecidos pelas normas legais vigentes (Peske e Baudet, 2003).

Após a colheita, normalmente, a semente advinda do campo está acompanhada de materiais indesejáveis, como sementes de má qualidade, deformadas, danificadas e infectadas por patógenos (Bicca et al., 1998) ou sementes de outras espécies, além de palhas, torrões e impurezas, que podem afetar a qualidade fisiológica dos lotes. Todos esses materiais indesejáveis, que acompanham a semente até a unidade de beneficiamento, precisam ser removidos em uma etapa subsequente (Oliveira, 1997).

As máquinas utilizadas no beneficiamento de sementes realizam as separações com base em diferenças físicas entre os componentes do lote, como tamanho, peso específico, forma, cor e textura (Oliveira, 1997), e, para que as operações sejam realizadas de maneira eficaz, é necessário o uso de um ou mais equipamentos especializados que permitam a remoção de materiais indesejáveis, promovendo um efetivo aprimoramento da qualidade dos lotes em termos de germinação e vigor (Martins et al., 2005).

A máquina de ar e peneiras remove o material mais leve, maior e menor do que as sementes.

Após a máquina de ar e peneiras, utiliza-se a mesa densimétrica ou gravitacional que classifica as sementes por massa específica, separando as sementes leves, imaturas, deterioradas e atacadas por insetos, das sementes não deterioradas e bem formadas, que possuem elevada qualidade (Linares, 1999).

Clarke (1985) obteve uma variação acima de 50\% na densidade das sementes de repolho quando comparadas as frações pesada e leve da descarga da mesa densimétrica, porém a diferença em densidade comparando as mesmas frações foi menor que $3 \%$ para sementes de alface. Buitrago et al. (1991) observaram, para sementes de feijão, que o uso exclusivo da máquina de ar e peneiras não melhorou a qualidade do lote de sementes, mas, associado à mesa gravitacional, houve eficiência na separação e distribuição de porções de qualidade superior. Observações semelhantes foram também feitas por Mertz et al. (2007) para sementes de Vigna unguiculata. Trabalhando com sementes de milho, Baudet e Misra (1991) e Fessel et al. (2003) verificaram que a mesa gravitacional foi eficiente para separar o lote em frações com qualidade distinta, sendo as sementes coletadas na descarga superior com melhor qualidade física e fisiológica, em comparação com as demais frações.

Alexandre e Silva (2001) avaliaram a eficiência da mesa gravitacional no beneficiamento de sementes de Vicia sativa L. (ervilhaca-comum) e verificaram que a separação das sementes pela densidade proporcionou alterações favoráveis no lote, cujas sementes de maior densidade apresentaram qualidade fisiológica superior. Também 
para sementes de soja (Deschamps, 2005) e milho-doce (Nascimento et al., 1994) a mesa gravitacional foi eficiente para separar as frações de sementes de acordo com a qualidade fisiológica.

$\mathrm{Na}$ maioria das pesquisas realizadas, observa-se que há concordância quanto à necessidade de remoção das sementes de menor densidade do lote, pois a pequena quantidade de substâncias de reserva pode proporcionar um lento desenvolvimento às plântulas (Giomo et al., 2004). Stanton (1984) já havia observado este fato para sementes de nabiça (Raphanus raphanistrum), em que plântulas oriundas de sementes de maior massa ( $>6 \mathrm{mg}$ ) se desenvolveram mais rapidamente e produziram mais flores em relação às sementes de menor massa $(<4 \mathrm{mg})$.

Diante da escassez de informações sobre o beneficiamento de sementes de nabo forrageiro, objetivouse com este trabalho avaliar a qualidade física e fisiológica de lotes de sementes da cultivar CATI AL-1000 obtidas nas diferentes etapas do beneficiamento.

\section{MATERIAL E MÉTODOS}

Foram utilizados dois lotes de sementes comerciais de nabo forrageiro, cultivar CATI AL-1000, ambos da safra de 2006, colhidos na região de Varginha, MG, localizada a $21^{\circ} 33^{\prime} 10^{\prime \prime}$ latitude S e $45^{\circ} 26^{\prime} 20^{\prime}$ " longitude W.

Inicialmente foi determinado o grau de umidade das sementes pelo método da estufa a $105 \pm 3{ }^{\circ} \mathrm{C}$ por 24 horas (Brasil, 1992), com 2 repetições de $10 \mathrm{~g}$ de sementes.

$\mathrm{O}$ experimento consistiu de uma combinação fatorial de dois lotes de sementes de nabo forrageiro e seis etapas do processo de beneficiamento (2X6), em delineamento inteiramente casualizado, com 4 repetições. Foram coletadas amostras de sementes antes de serem beneficiadas, depois da máquina de ar e peneiras e nas diferentes descargas (superior, intermediária superior, intermediária inferior e inferior) da mesa de gravidade.

As sementes foram beneficiadas em máquina de ar e peneiras (MAP) Vence Tudo ${ }^{\circledR}$ modelo CA-25, utilizando as peneiras $3,0-2,0 \mathrm{~mm}, 1,1 / 1,0 \mathrm{x} 13 \mathrm{~mm}$ e $1,8-2,0 \mathrm{~mm}$ (Nascimento et al., 2007) e, em seguida, conduzidas para mesa de gravidade marca Oliver ${ }^{\circledR}$ de formato retangular. As seções de descarga foram ajustadas de maneira a permitir maior concentração de materiais indesejáveis na descarga inferior. Após a estabilização do funcionamento dos equipamentos, coletaram-se amostras de $5 \mathrm{~kg}$ de sementes na saída da máquina de ar e peneiras e nas descargas da mesa de gravidade (superior, intermediárias superior e inferior e inferior), além das sementes não beneficiadas .

As amostras foram reduzidas em divisor de solo, para obtenção da amostra de trabalho de $30 \mathrm{~g}$ para a análise de pureza, determinando-se a porcentagem de sementes puras, material inerte (g/peso) e outras sementes (número/ peso), conforme as Regras para Análise de Sementes - RAS (Brasil, 1992).

O peso de mil sementes foi determinado segundo metodologia descrita nas RAS (Brasil 1992).

No teste de germinação, a semeadura foi realizada sobre areia, em caixas do tipo gerbox, colocadas em câmara B.O.D. regulada à temperatura $20-30{ }^{\circ} \mathrm{C}$, com fotoperíodo de 12 horas. Foram utilizadas quatro repetições de 50 sementes e os resultados expressos em porcentagem de plântulas normais no terceiro dia (primeira contagem), sendo o teste encerrado no sétimo dia, computando a porcentagem de plântulas normais. $\mathrm{O}$ índice de velocidade de germinação foi calculado segundo a fórmula proposta por Maguire (1962), computando-se o número de sementes com emissão de, pelo menos, $1 \mathrm{~mm}$ de radícula.

A percentagem de emergência foi realizada em substrato solo e areia na proporção 1:2 em bandejas plásticas. A umidade do substrato foi ajustada para $60 \%$ da capacidade de retenção. Após a semeadura, de quatro repetições de 50 sementes, as bandejas foram mantidas à temperatura de $20{ }^{\circ} \mathrm{C}$. A partir do início da emergência foram realizadas avaliações diárias, computando-se o estande inicial ao $3^{\circ}$ dia e o número de plântulas emergidas até a estabilização do estande. $\mathrm{O}$ índice de velocidade de emergência foi determinado segundo a fórmula proposta por Maguire (1962).

A massa seca de parte aérea das plântulas foi determinada utilizando as plântulas normais provenientes do teste de emergência. As plântulas foram cortadas rente ao substrato, postas em sacos de papel e em estufa com circulação forçada de ar a $60{ }^{\circ} \mathrm{C}$, até peso constante; após esse período as plântulas foram pesadas em balança com precisão de $1 \mathrm{mg}$ e o valor obtido dividido pelo número de sementes utilizadas, obtendo os dados em mg por semente.

O teste de sanidade foi pelo método do papel de filtro ou blotter test modificado, com o uso de 2,4-D e congelamento, utilizando-se 200 sementes, divididas em 8 repetições de 25 sementes dispostas em placas de Petri sobre três folhas de papel de filtro embebidas com água destilada, 2,4-D e ágar. As placas foram mantidas à temperatura de $-8^{\circ} \mathrm{C}$ por um dia e por 5 dias para incubação em câmara B.O.D. a $22-25^{\circ} \mathrm{C}$, com fotoperíodo de 12 horas. Foi avaliada a presença de fungos nas sementes, identificando-os com auxilio de lupa 
e microscópico estereoscópico.

Os dados experimentais foram previamente submetidos aos testes de normalidade dos resíduos e homocedasticidade das variâncias. Os dados de germinação, estande inicial e emergência foram transformados em arcsen, e submetidos à analise de variância. As médias foram comparadas pelos testes de Scott-knott ou Tukey a 5\% de probabilidade. As análises estatísticas foram realizadas com o auxílio do programa estatístico SAS $^{\circledR}$ (SAS INSTITUTE, 1990).

\section{RESULTADOS E DISCUSSÃO}

O grau de umidade das sementes foi de $8 \%$ para ambos os lotes por ocasião da realização dos testes de avaliação da qualidade após beneficiamento e secagem natural à sombra.

Nas diferentes etapas do beneficiamento, observou-se que a pureza variou de 65,4 a $99,7 \%$ para o lote um e de 70,5 a $98,4 \%$ para o lote dois (Tabela 1 ).

TABELA 1. Sementes puras (\%) e peso de mil sementes (g) dos dois lotes (1 e 2 ) de sementes de nabo forrageiro, coletadas nas diferentes etapas do beneficiamento.

\begin{tabular}{lcccc}
\hline \multirow{2}{*}{\multicolumn{1}{c}{ Tratamentos }} & \multicolumn{2}{c}{ Sementes Puras $(\%)$} & \multicolumn{2}{c}{ Peso de mil sementes $(\mathrm{g})$} \\
\cline { 2 - 5 } & 1 & 2 & 1 & 2 \\
\hline Testemunha - Não beneficiada & $84,4 \mathrm{Ab}$ & $71,6 \mathrm{Ab}$ & $9,86 \mathrm{Bb}$ & $10,58 \mathrm{Ac}$ \\
Máquina de ar e peneiras (MAP) & $98,7 \mathrm{Aa}$ & $96,8 \mathrm{Ba}$ & $10,70 \mathrm{Ab}$ & $11,02 \mathrm{Ab}$ \\
Densimétrica - descarga Superior & $99,7 \mathrm{Aa}$ & $98,4 \mathrm{Ba}$ & $12,52 \mathrm{Aa}$ & $12,04 \mathrm{Aa}$ \\
Densimétrica - descarga Intermediária Superior & $99,2 \mathrm{Aa}$ & $97,4 \mathrm{Ba}$ & $10,38 \mathrm{Ab}$ & $11,12 \mathrm{Ab}$ \\
Densimétrica - descarga Intermediária Inferior & $97,3 \mathrm{Aa}$ & $96,0 \mathrm{Ba}$ & $8,71 \mathrm{Bc}$ & $9,95 \mathrm{Ac}$ \\
Densimétrica - descarga Inferior & $65,4 \mathrm{Bc}$ & $70,5 \mathrm{Ab}$ & $6,58 \mathrm{Bd}$ & $7,95 \mathrm{Ad}$ \\
\hline \multicolumn{2}{c}{ Coeficiente de variação $(\%)$} & \multicolumn{3}{c}{3,42} \\
\hline
\end{tabular}

Médias seguidas pela mesma letra minúscula na coluna e maiúscula na linha, não diferem pelo teste de Scott-Knott, a 5\%.

De acordo com a Instrução Normativa (IN) $n^{\circ} 30$, do Ministério da Agricultura Pecuária e Abastecimento -MAPA (Brasil, 2008), o padrão mínimo de pureza para comercialização de sementes certificadas do gênero Raphanus, para a safra de 2008/09, é de $98 \%$. Dessa forma, o beneficiamento possibilitou alcançar o padrão mínimo para comercialização, para as sementes classificadas nas descargas superiores e intermediária superior do lote um e apenas na descarga superior do lote dois. Estes resultados demonstram a importância do beneficiamento das sementes de nabo forrageiro.

As impurezas observadas em ambos os lotes eram constituídas de palhas, pedras e outras sementes, sendo encontrado principalmente mistura com sementes de
Brachiaria brizantha, Zea maiz, Helianthus annus, Bidens pilosa e Hyptis suoveolons.

Observa-se, pelo peso de mil sementes, que as mais pesadas, independente do lote, são provenientes da descarga superior, em relação à testemunha, indicando a eficiência da classificação quando se utiliza como base de separação a densidade (Tabela 1).

O potencial fisiológico das sementes de nabo forrageiro do lote 2 foi superior ao lote 1 em relação à germinação, primeira contagem da germinação, estande inicial, emergência, massa seca da parte aérea de plântulas, índice de velocidade de germinação e de emergência (Tabela 2), na caracterização do perfil dos lotes.

TABELA 2. Germinação - G (\%), primeira contagem - PC (\%), estande inicial - EI (\%), emergência - E (\%), massa seca da parte aérea de plântulas - MS (mg/sementes) e índice de velocidade de germinação - IVG e de emergência - IVE dos dois lotes de sementes de nabo forrageiro, antes do beneficiamento.

\begin{tabular}{cccccccc}
\hline Lotes & G & PC & EI & E & MS & IVG & IVE \\
\hline 1 & $43 \mathrm{~b}$ & $23 \mathrm{~b}$ & $23 \mathrm{~b}$ & $57 \mathrm{~b}$ & $0,0056 \mathrm{~b}$ & $23,12 \mathrm{~b}$ & $14,80 \mathrm{~b}$ \\
2 & $68 \mathrm{a}$ & $34 \mathrm{a}$ & $37 \mathrm{a}$ & $72 \mathrm{a}$ & $0,0077 \mathrm{a}$ & $23,58 \mathrm{a}$ & $16,67 \mathrm{a}$ \\
\hline
\end{tabular}

Médias seguidas pela mesma letra minúscula na coluna, não diferem pelo teste de Scott-Knott, a 5\%. 
Pelo teste de primeira contagem de germinação, o beneficiamento das sementes não ocasionou diferença significativa entre os tratamentos (dados não apresentados); o mesmo não foi observado para os demais testes (Tabela 3). Pelo teste de germinação, observa-se acréscimo de $9 \%$ e $7 \%$ para sementes beneficiadas na máquina de ar e peneiras e na descarga superior da mesa de gravidade, respectivamente. Somente estas frações apresentaram germinação superior à mínima estabelecida para espécies do gênero Raphanus que, de acordo com a IN n³0, é de $60 \%$ para sementes certificadas.

TABELA 3 . Germinação - G (\%), estande inicial - EI (\%), emergência - E (\%) e massa seca da parte aérea de plântulas - MS (mg/sementes) dos lotes de sementes de nabo forrageiro, após as diferentes etapas do beneficiamento.

\begin{tabular}{lcccc}
\hline \multicolumn{1}{c}{ Tratamentos } & G & EI & E & MS \\
\hline Testemunha - Não beneficiada & $57 \mathrm{ab}$ & $41 \mathrm{a}$ & $71 \mathrm{ab}$ & $0,0081 \mathrm{a}$ \\
Máquina de ar e peneiras (MAP) & $66 \mathrm{a}$ & $34 \mathrm{a}$ & $73 \mathrm{ab}$ & $0,0079 \mathrm{a}$ \\
Densimétrica - descarga Superior & $64 \mathrm{a}$ & $46 \mathrm{a}$ & $79 \mathrm{a}$ & $0,0080 \mathrm{a}$ \\
Densimétrica - descarga Intermediária Superior & $55 \mathrm{ab}$ & $34 \mathrm{a}$ & $71 \mathrm{ab}$ & $0,0079 \mathrm{a}$ \\
Densimétrica - descarga Intermediária Inferior & $50 \mathrm{ab}$ & $17 \mathrm{~b}$ & $61 \mathrm{~b}$ & $0,0059 \mathrm{a}$ \\
Densimétrica - descarga Inferior & $42 \mathrm{~b}$ & $8 \mathrm{c}$ & $34 \mathrm{c}$ & $0,0022 \mathrm{~b}$ \\
\hline \multicolumn{1}{c}{ Coeficiente de variação (\%) } & 21,15 & 32,89 & 14,55 & 11,82 \\
\hline
\end{tabular}

Médias seguidas pela mesma letra minúscula na coluna, não diferem pelo teste de Tukey, a 5\%.

Resultados semelhantes, de superioridade na germinação após classificação das sementes na mesa de gravidade, também foram observados para sementes de couve-flor (Gadotti et al., 2006) e cebola (Stradioto Neto et al., 1992).

Com relação aos testes de vigor (Tabela 3), acréscimos superiores na qualidade das sementes foram observados quando se utilizou a máquina de ar e peneiras, sendo que estes acréscimos também foram detectados nas outras etapas do beneficiamento em relação às sementes classificadas nas descargas inferiores.

Para as sementes coletadas nas descargas intermediárias inferiores e inferiores, resultados inferiores são justificados, pois menor peso específico frequentemente se relaciona ao menor vigor das sementes. Este fato também foi verificado por Buitrago et al. (1991) e Fantinatti et al. (2002) para sementes de feijão, Baudet e Misra (1991) para sementes de milho, Krueger et al. (2007) para sementes de milho, Alexandre e Silva (2001) para sementes de ervilhaca-comum, Nascimento et al. (1994) para sementes de milho-doce e Giomo et al. (2004) para sementes de café.

Para o índice de velocidade de germinação, foram observadas diferenças entre as sementes da testemunha e as dos tratamentos da máquina de ar e peneiras e descarga inferior do lote 1 (Tabela 4). Observa-se que o beneficiamento foi mais eficiente na separação dos lotes de pior qualidade, separando o lote 1 , em três níveis de qualidade, tanto para o IVG quanto para o IVE. Para o lote 2 não houve diferenças significativas entre os tratamentos. A inferioridade do lote 1 em relação ao lote 2 foi observada tanto no IVG como no IVE, à semelhança dos resultados obtidos na Tabela 2. Para o índice de velocidade de emergência do lote 2 , observou-se diferença nos resultados das descargas intermediária inferior e inferior em relação aos demais tratamentos.

Os fungos detectados no teste de sanidade foram Aspergillus flavus, A. niger, Penicilium e Alternaria alternata (Tabela 5). Destaca-se a espécie Penicilium, presente em porcentagem superior a $40 \%$ em média para os dois lotes. Segundo Lucca-Filho (1995), os danos causados pelas espécies de fungo Penicillium são variáveis, como perda da germinação, descoloração das sementes, aquecimento da massa de sementes e produção de toxinas.

Pelos resultados, não foi possível observar que sementes de menor densidade apresentam maior incidência de Penicillium, como observado por Buitrago et al. (1991) para sementes de feijão e Alexandre e Silva (2001) para ervilhaca-comum. 
TABELA 4. Índice de velocidade de germinação - IVG e índice de velocidade de emergência - IVE dos dois lotes (1 e 2) de sementes de nabo forrageiro, após as diferentes etapas do beneficiamento.

\begin{tabular}{lcccc}
\hline \multirow{2}{*}{\multicolumn{1}{c}{ Tratamentos }} & \multicolumn{2}{c}{ IVG } & \multicolumn{2}{c}{ IVE } \\
\cline { 2 - 5 } & 1 & 2 & 1 & 2 \\
\hline Testemunha - Não beneficiada & $20,08 \mathrm{Bb}$ & $23,34 \mathrm{Aa}$ & $11,92 \mathrm{Bab}$ & $16,67 \mathrm{Aa}$ \\
Máquina de ar e peneiras (MAP) & $23,12 \mathrm{Aa}$ & $23,58 \mathrm{Aa}$ & $14,79 \mathrm{Aa}$ & $17,44 \mathrm{Aa}$ \\
Densimétrica - descarga Superior & $21,38 \mathrm{Bab}$ & $23,84 \mathrm{Aa}$ & $9,78 \mathrm{Ab}$ & $16,49 \mathrm{Aa}$ \\
Densimétrica - descarga Intermediária Superior & $21,39 \mathrm{Aab}$ & $22,31 \mathrm{Aa}$ & $12,18 \mathrm{Bab}$ & $16,27 \mathrm{Aa}$ \\
Densimétrica - descarga Intermediária Inferior & $18,49 \mathrm{Bb}$ & $23,68 \mathrm{Aa}$ & $10,43 \mathrm{Bb}$ & $11,39 \mathrm{Ab}$ \\
Densimétrica - descarga Inferior & $10,96 \mathrm{Bc}$ & $21,67 \mathrm{Aa}$ & $3,80 \mathrm{Bc}$ & $9,31 \mathrm{Ab}$ \\
\hline \multicolumn{1}{c}{6,53} & \multicolumn{3}{c}{12,49} \\
\hline
\end{tabular}

Médias seguidas pela mesma letra minúscula na coluna e maiúscula na linha, não diferem pelo teste de Tukey, a $5 \%$.

TABELA 5. Porcentagem de incidência dos fungos Aspergilus flavus, Aspergilus niger, Penicillium e Alternaria alternata nos dois lotes (1 e 2) de sementes de nabo forrageiro, após as diferentes etapas do beneficiamento.

\begin{tabular}{lcccccccc}
\hline \multirow{2}{*}{\multicolumn{1}{c}{ Tratamentos }} & \multicolumn{3}{c}{ A. flavus } & \multicolumn{2}{c}{ A. niger } & \multicolumn{2}{c}{ Penicillium } & \multicolumn{2}{c}{ A. alternata } \\
\cline { 2 - 9 } & 1 & 2 & 1 & 2 & 1 & 2 & 1 & 2 \\
\hline Testemunha - Não beneficiada & 25 & 4 & 0 & 6 & 77 & 42 & 10 & 15 \\
Máquina de ar e peneiras (MAP) & 19 & 2 & 1 & 4 & 52 & 24 & 5 & 14 \\
Densimétrica - descarga Superior & 4 & 6 & 6 & 5 & 44 & 27 & 11 & 18 \\
Densimétrica - descarga Intermediária Superior & 19 & 2 & 0 & 6 & 64 & 50 & 17 & 17 \\
Densimétrica - descarga Intermediária Inferior & 18 & 0 & 4 & 2 & 73 & 18 & 9 & 16 \\
Densimétrica - descarga Inferior & 54 & 5 & 1 & 1 & 72 & 10 & 11 & 7 \\
\hline
\end{tabular}

\section{CONCLUSÃO}

O beneficiamento em máquina de ar, peneiras e mesa gravitacional contribui para o aprimoramento da qualidade fisiológica das sementes de nabo forrageiro.

A máquina de ar e peneiras e a mesa gravitacional são equipamentos eficientes para a separação do lote de sementes de nabo forrageiro em frações com qualidade física e fisiológica distintas.

As sementes de nabo forrageiro de menor densidade apresentam qualidade fisiológica inferior.

\section{REFERÊNCIAS}

ALEXANDRE, A.D.; SILVA, W.R. Mesa gravitacional e qualidade física de sementes de ervilhaca-comum (Vicia sativa L.). Revista Brasileira de Sementes, v.23, n.1, p.167174, 2001.

BAUDET, L.; MISRA, M. Atributos de qualidade de sementes de milho beneficiadas em mesa de gravidade. Revista Brasileira de Sementes, v.13, n.2, p.101-104, 1991.

BICCA, F.M.; BAUDET, L.; JAIMEZIMMER, G. Separação de sementes manchadas de lotes de sementes de arroz, utilizando a mesa de gravidade e sua influência na qualidade sanitária. Revista Brasileira de Sementes, v.20, n.1, p.106111, 1998.

BRASIL. Ministério da Agricultura, Pecuária e do Abastecimento Gabinete do Ministro. Instrução Normativa $\mathrm{n}^{\circ} 30$, de 21 de maio de 2008. Publicado no Diário Oficial da União, Poder Executivo, Brasília, DF, 23 de maio de 2008, Seção 1, p.45. Disponível em: http://extranet.agricultura. gov.br/sislegis-consulta/consultarLegislacao.do?operacao= visualizar\&id=18678. Acesso em: 04 ago. 2008.

BRASIL. Ministério da Agricultura e Reforma Agrária. Secretaria Nacional de Defesa Agropecuária. Departamento Nacional de Defesa Vegetal. Coordenação de Laboratório Vegetal. Regras para análise de sementes. Brasília, DF, 
1992. $365 \mathrm{p}$.

BUITRAGO, I.C.; VILLELE, F.A.; TILLMANN, M.A.; SILVA, J.B. Perdas de qualidade de sementes de feijão beneficiadas em máquina de ventiladores e peneiras e mesa de gravidade. Revista Brasileira de Sementes, v.13, n.2, p.99-104, 1991.

CLARKE, B. Cleaning seeds by fluidization. Journal of Agricultural Engineering Research, v.31, n.3, p.231-42, 1985.

DERPSCH, R.; CALEGARI, A. Plantas para adubação verde de inverno no sudoeste do Paraná. Londrina: IAPAR, 1992. 78p. (IAPAR. Circular, 73).

DESCHAMPS, L.H. Qualidade das sementes de soja e de repasse beneficiados em mesa de gravidade. 2005. $46 \mathrm{f}$. Dissertação (Mestrado em Ciência e Tecnologia de Sementes) - Faculdade de Agronomia Eliseu Maciel, Universidade de Pelotas, Pelotas.

FANTINATTI, J.B.; HONÓRIO, S.L.; RAZERA, L.F. Qualidade de sementes de feijão de diversas densidades obtidas na mesa gravitacional. Revista Brasileira de Sementes, v.24, n.1, p.24-32, 2002.

FESSEL, S.A.; SADER, R.; PAULA, R.C.; GALLI, J.A. Avaliação da qualidade física, fisiológica e sanitária de sementes de milho durante o beneficiamento. Revista Brasileira de Sementes, v.25, n.2, p.70-76, 2003.

GADOTTI, G.I.; CORREA, C.L.; LUCCA FILHO, O.A.; VILLELA, F.A. Qualidade de sementes de couve brócolis beneficiadas em mesa densimétrica. Revista Brasileira de Sementes, v.28, n.2, p.123-127, 2006.

GIOMO, G.S.;RAZERA,L.F.; GALLO,P.B. Beneficiamento e qualidade de sementes de café arábica. Bragantia, v.63, n. 2, p.291-297, 2004.

KRUEGER, N.A.; BERN, C.J.; MISRA, M.K.; ADAM, K.M. Gravity table sorting of commodity corn. Applied Engineering in Agriculture, v.23, n.3, p.319-325, 2007.

LINARES, J.B.F. Qualidade de sementes de feijoeiro (Phaseolus vulgaris L.) de diversas densidades obtidas na mesa gravitacional. 1999. 50 f. Dissertação (Mestrado em Engenharia Agrícola) - Universidade Estadual de Campinas, Campinas.

LUCCA-FILHO, O.A. Patologia de sementes. Brasília, DF: ABEAS, 1995. 53p. (ABEAS. Curso de Tecnologia de Sementes. Módulo, 4).
MAGUIRE, J.D. Speed of germination-aid in selection and evaluation for seedlig emergence and vigor. Crop Science, v.2, n.2, p.176-177, 1962.

MARTINS, G.N.; SILVA, R.F.; ARAÚJO, E.F.; PEREIRA, M.G.; VIEIRA, H.D.; VIANA, A.P. Influencia do tipo de fruto, peso específico das sementes e período de armazenamento na qualidade fisiológica de sementes de mamão do grupo formoso. Revista Brasileira de Sementes, v.27, n.2, p.12-17, 2005.

MERTZ, L.M.; HENNING, F.A.; MAIA, M.S.; MENEGHELLO, G.E.; HENRIQUES, A.; MADAIL, R. Qualidade fisiológica e sanitária de sementes de feijão-miúdo beneficiadas em mesa gravitacional. Revista Brasileira de Sementes, v.29, n.3, p.1-8, 2007.

MUZILLI, O. Manejo da matéria orgânica no sistema plantio direto: a experiência no Estado do Paraná. Informações Agronômicas, Piracicaba, n.100, p.6-10, 2002.

NASCIMENTO, W.M.; FREITAS, R.A.; ARAUJO, E.F. Beneficiamento de sementes de hortaliças. In: CURSO INTERNACIONAL SOBRE PRODUCCIÓN Y TECNOLOGIA DE SEMILLAS DE HORTALIZAS, 2007, Palmira. Memorias... Palmira: Universidad Nacional de Colombia, Sede Palmira, 2007. 1 CD ROM.

NASCIMENTO, W.M.; PESSOA, H.B.S.V.; BOITEUX, L.S. Qualidade fisiológica de sementes de milho-doce submetidas a diferentes processos de colheita, debulha e beneficiamento. Pesquisa Agropecuária Brasileira, v.29, n.8, p.1211-1214, 1994.

OLIVEIRA, A. de. Influência de danos mecânicos ocorridos no beneficiamento sobre a qualidade fisiológica, sanitária e potencial de armazenamento de sementes de soja. 1997. 90 f. Dissertação (Mestrado) - Universidade Estadual Paulista, Jaboticabal.

PESKE, S.T.;BAUDET,L. Treinamentoembeneficiamento de sementes para encarregados de UBS da Coopervale. Abelardo Luz: Coopervale, 2003. 45p.

SAS INSTITUTE. SAS/STAT user's guide. Version 6. 4.ed. Cary: Statistical Analysis System Institute, 1990. 846p.

STANTON, M.L. Developmental and genetic sources of seed weight variation in Raphanus raphanistrum $\mathrm{L}$. (Brassicaceae). American Journal of Botany, v.71, n.8, p.1090-1098. 1984.

STRADIOTO NETO, J.; GARCIA, A.; MACIEL, V.D.; LUCCA, O.A. Effect of seed physiological and sanitary quality on the performance of onion seedlings. Pesquisa Agropecuária Brasileira, v.27, n.4, p.575-580, 1992. 